\title{
Communication \\ Prediction of SARS-CoV-2 Omicron Variant Immunogenicity, Immune Escape and Pathogenicity, through the Analysis of Spike Protein-Specific Core Unique Peptides
}

\author{
Evangelos Kontopodis ${ }^{1,2}$, Vasileios Pierros ${ }^{1}$, Dimitrios J. Stravopodis ${ }^{2}$ (D) and George T. Tsangaris ${ }^{1, *(D)}$ \\ 1 Proteomics Research Unit, Biomedical Research Foundation of the Academy of Athens, 11527 Athens, Greece; \\ kontopodisv@hotmail.gr (E.K.); pierrosv@gmail.com (V.P.) \\ 2 Section of Cell Biology and Biophysics, Department of Biology, School of Science, National and Kapodistrian \\ University of Athens, 15701 Athens, Greece; dstravop@biol.uoa.gr \\ * Correspondence: gthtsangaris@bioacademy.gr; Tel.: +30-210-659-7075
}

check for updates

Citation: Kontopodis, E.; Pierros, V.; Stravopodis, D.J.; Tsangaris, G.T. Prediction of SARS-CoV-2 Omicron Variant Immunogenicity, Immune Escape and Pathogenicity, through the Analysis of Spike Protein-Specific Core Unique Peptides. Vaccines 2022, 10, 357. https://doi.org/10.3390/ vaccines 10030357

Academic Editor: Vasso

Apostolopoulos

Received: 21 January 2022

Accepted: 22 February 2022

Published: 24 February 2022

Publisher's Note: MDPI stays neutral with regard to jurisdictional claims in published maps and institutional affiliations.

Copyright: (c) 2022 by the authors. Licensee MDPI, Basel, Switzerland. This article is an open access article distributed under the terms and conditions of the Creative Commons Attribution (CC BY) license (https:// creativecommons.org/licenses/by/ $4.0 /)$.

\begin{abstract}
The recently discovered Omicron variant of the SARS-CoV-2 coronavirus has raised a new, global, awareness. In this study, we identified the Core Unique Peptides (CrUPs) that reside exclusively in the Omicron variant of Spike protein and are absent from the human proteome, creating a new dataset of peptides named as SARS-CoV-2 $\mathrm{CrUPs}$ against the human proteome ( $\mathrm{C} / \mathrm{H}-\mathrm{CrUPs}$ ), and we analyzed their locations in comparison to the Alpha and Delta variants. In Omicron, $115 \mathrm{C} / \mathrm{H}-$ CrUPs were generated and $119 \mathrm{C} / \mathrm{H}-\mathrm{CrUPs}$ were lost, almost four times as many compared to the other two variants. At the Receptor Binding Motif (RBM), 8 mutations were detected, resulting in the construction of 28 novel C/H-CrUPs. Most importantly, in the Omicron variant, new C/H-CrUPs carrying two or three mutant amino acids were produced, as a consequence of the accumulation of multiple mutations in the RBM. These C/H-CrUPs could not be recognized in any other viral Spike variant. Our findings indicated that the virus binding to the ACE2 receptor is facilitated by the herein identified $\mathrm{C} / \mathrm{H}-\mathrm{CrUPs}$ in contact point mutations and Spike cleavage sites, while the immunoregulatory NF9 peptide is not detectably affected. Thus, the Omicron variant could escape immune-system attack, while the strong viral binding to the ACE2 receptor leads to the highly efficient fusion of the virus to the target cell. However, the intact NF9 peptide suggests that Omicron exhibits reduced pathogenicity compared to the Delta variant.
\end{abstract}

Keywords: core unique peptide; COVID-19; immune escape; infectiveness; mutation; Omicron variant; pathogenicity; SARS-CoV-2; Spike protein; Uniquome

\section{Introduction}

The SARS-CoV-2 virus has a high mutagenesis frequency, hitherto producing 63 different variants with 39 considered as the most predominant forms, including Delta, the dominant variant of the 4th pandemic wave [1]. Recently, a new variant, Omicron (B.1.1.529), was identified in South Africa. Omicron is characterized by 30 amino acid changes, three small deletions, and one small insertion in Spike protein, as compared to the original virus, with 15 of them residing in the Receptor Binding Domain (RBD) from 319 to 541 amino acid residues [2].

In our previous studies, we have defined as Unique Peptides (UPs) the peptides whose amino acid sequence appears only in one protein across a given proteome. We also introduced the term of Core Unique Peptides (CrUPs), which are the peptides with a minimum amino acid sequence length that appear only in one protein across a given proteome, thus having a unique signature for a particular protein identification [3]. Therefore, each peptide of any size that contains a CrUP is considered a UP. Peptides of bigger sizes than CrUPs being constructed by continuous CrUPs are considered as Composite Core Unique Peptides (CmUPs). Hitherto, our results regarding the analysis of CrUPs in 
different species and organisms strongly suggest that CrUPs constitute a concrete group of peptides within a given proteome, with specialized properties and functions Thereby, we have introduced the new term "Uniquome", which is defined as the total set of UPs belonging to a given proteome and serving as its unique molecular signature. Hence, to map the UP landscape of a proteome under examination, we have herein developed a novel and advanced bioinformatics tool, including big data analysis, and we have applied this tool for the analysis of Uniquome typifying all model organisms. In Homo sapiens, the analysis of the 20,430 reviewed proteins resulted in the identification of 7,263,888 CrUPs which construct the human Uniquome (hUniquome) ([3] and Kontopodis et al., 2022 (manuscript in preparation)).

Most importantly, to elucidate SARS-CoV-2 virus-host organism interactions, we have further designed a novel bioinformatics platform to analyze the Core Unique Peptides (CrUPs) of the SARS-CoV-2 virus against the human proteome (C/H-CrUPs) [1]. C/HCrUPs represent a completely new set of peptides, which are the shortest in length peptides in a viral proteome that do not exist in the human proteome [3]. Based on their properties, the viral C/H-CrUPs could advance our knowledge regarding virus-host interactions, immune system response(s), and infectiveness and pathogenicity of the virus. Moreover, most importantly, they can be used as antigenic and diagnostic peptides, and likely druggable targets for successful therapeutic treatments.

In the present study, we have identified, cataloged, and analyzed Omicron-specific $\mathrm{C} / \mathrm{H}-\mathrm{CrUPs}$ in order to illuminate the mechanisms controlling infectivity, immune escape, and pathogenicity of the new variant.

\section{Materials and Methods}

\subsection{Methods}

In our previous, recent studies, we developed a bioinformatics tool that can extract the Core Unique Peptides (CrUPs) from a given proteome, thus creating its Uniquome (Figure S1) [1,3]. We have expanded this tool by introducing a new feature that can extract the CrUPs of each individual protein of a given proteome (target) versus the proteins of a reference proteome. This new feature, like the initial implementation, will split each protein in the target proteome to all possible peptides of length minimum (4 amino acids) to length maximum (100 amino acids), and search them against the reference proteome. Each search will exclude all peptides that contain a smaller peptide already identified as CrUP (Figure S2).

For the present study, we have engaged this new feature of our tool. We created a "custom" proteome consisting of sequences from all variants of the SARS-CoV-2 Spike proteins and used it as the target versus the human proteome. The tool produces as output the $\mathrm{C} / \mathrm{H}-\mathrm{CrUPs}$ per protein of the target proteome, thus revealing the CrUPs for each Spike variant versus the human proteome.

Once we obtained the desired data, we ran a meta-analysis to identify how many $\mathrm{C} / \mathrm{H}-\mathrm{CrUPs}$ remained the same, or were added or lost on each variant versus the wildtype Spike protein. For this analysis, initially we took the identified $\mathrm{C} / \mathrm{H}-\mathrm{CrUPs}$ of the wild-type sequence and checked their presence against the respective $\mathrm{C} / \mathrm{H}-\mathrm{CrUPs}$ of the other variants. We only cared for the amino acid sequence and not the position this could be found within the protein. If the sequence was found, then we considered the peptide to be the same, otherwise we considered it to be lost on the examined variant. Next, we analyzed the identified $\mathrm{C} / \mathrm{H}-\mathrm{CrUPs}$ of each variant versus the wild-type sequence. If the peptide was detected only on the variant's $\mathrm{C} / \mathrm{H}-\mathrm{CrUPs}$, then we considered it as added. This meta-analysis also provided us with the position of each C/H-CrUP within the Spike protein, which we used to determine the area (e.g., RBD, RBM and S-cleavage site, as obtained by the Stanford COVID-19 Database) they resided in. 


\subsection{Databases}

All proteomes and proteins were obtained from Uniprot. SARS-CoV-2 wild-type and variant sequences, and mutations were obtained from the Stanford COVID-19 Database (https: / covdb.stanford.edu/page/mutation-viewer/, accessed on 23 December 2021).

\section{Results and Discussion}

\subsection{Mapping the C/H-CrUPs Landscape of Spike Protein of the SARS-CoV-2 Omicron Variant}

SARS-CoV-2 virus seems to be highly mutated, so far producing more than 60 distinct variants. Hitherto, the highest pathogenic form is the Delta variant (B.1.617.2), with 10 different sub-variants. Recently, a novel variant called Omicron has been identified. It is characterized by 30 amino acid changes, three small deletions, and one small insertion in the Spike protein area, as compared to the wild-type viral respective sequence (Figure S3) [2]. Out of these genetic changes, 15 reside in the Receptor Binding Domain (RBD) from amino acid position 318 to 541, and two are located around the S-cleavage site(s) (Figure S3).

Advanced bioinformatics analysis of the Omicron variant Spike protein showed that it contains $983 \mathrm{C} / \mathrm{H}-\mathrm{CrUPs}$, a number that is comparable to the one of wild-type Spike proteins (987 C/H-CrUPs) and to the mean $\pm \mathrm{SD}$ value of Spike protein-specific $\mathrm{C} / \mathrm{H}-$ CrUPs (983 \pm 2 C/H-CrUPs) (Table 1). Omicron variant Spike protein contains 34 mutations in total, which is the highest number of identified mutations among all virus variants.

Table 1. SARS-CoV-2 Spike protein C/H-CrUPs across variants, as compared to the wild-type virus respective sequence.

\begin{tabular}{|c|c|c|c|c|c|c|c|}
\hline \multirow[b]{2}{*}{ Variant } & \multicolumn{7}{|c|}{ Spike Protein } \\
\hline & C/H-CrUPs & $\begin{array}{c}\text { Same } \\
\text { C/H-CrUPs }\end{array}$ & $\begin{array}{l}\% \text { of Same } \\
\text { C/H-CrUPs }\end{array}$ & $\begin{array}{c}\text { New } \\
\text { C/H-CrUPs }\end{array}$ & $\begin{array}{l}\% \text { of New } \\
\text { C/H-CrUPs }\end{array}$ & $\begin{array}{c}\text { Lost } \\
\text { C/H-CrUPs }\end{array}$ & $\begin{array}{l}\% \text { of Lost } \\
\text { C/H-CrUPs }\end{array}$ \\
\hline Wild-type virus & 987 & & & & & & \\
\hline Alpha (B.1.1.7) + (Q1-Q4) & 982 & 931 & 94.8 & 51 & 5.2 & 56 & 5.7 \\
\hline Alpha (B.1.1.7 + E484K) & 983 & 928 & 94.4 & 55 & 5.6 & 59 & 6.0 \\
\hline Alpha (B.1.1.7 + L452R) & 981 & 936 & 95.4 & 45 & 4.6 & 51 & 5.2 \\
\hline Alpha (B.1.1.7 + S494P) & 981 & 936 & 95.4 & 45 & 4.6 & 51 & 5.2 \\
\hline Beta (B.1.351) & 981 & 954 & 97.2 & 27 & 2.8 & 33 & 3.3 \\
\hline Beta (B.1.351 + E516Q) & 981 & 949 & 96.7 & 32 & 3.3 & 38 & 3.8 \\
\hline $\begin{array}{c}\text { Beta }(\text { B.1.351 + L18F) } \\
(\text { B.1.351.2-3) }\end{array}$ & 979 & 948 & 96.8 & 31 & 3.2 & 39 & 3.9 \\
\hline Beta (B.1.351 + P384L) & 980 & 949 & 96.8 & 31 & 3.2 & 38 & 3.9 \\
\hline Gamma (P.1) (P.1.1 - P.1.2) & 985 & 930 & 94.4 & 55 & 5.6 & 57 & 5.8 \\
\hline Gamma (P1 + P681H) & 985 & 930 & 94.4 & 55 & 5.6 & 57 & 5.8 \\
\hline Delta (B.1.617.2) & 984 & 948 & 96.3 & 36 & 3.7 & 39 & 4.0 \\
\hline Delta (B.1.617.2 + E484Q) & 984 & 945 & 96.0 & 39 & 3.4 & 42 & 4.3 \\
\hline Delta (B.1.617.2 + K417N) & 984 & 944 & 95.9 & 40 & 4.1 & 43 & 4.4 \\
\hline Delta (B.1.617.2 + Q613H) & 984 & 947 & 96.2 & 37 & 3.8 & 40 & 4.1 \\
\hline Delta (AY.1) & 984 & 944 & 95.9 & 40 & 4.7 & 43 & 4.1 \\
\hline Delta (AY.2) & 985 & 939 & 95.3 & 46 & 4.8 & 48 & 4.9 \\
\hline $\begin{array}{c}\text { Delta (AY.3 - AY.8) + } \\
\text { (AY.12) }\end{array}$ & 983 & 951 & 96.7 & 32 & 3.3 & 36 & 3.7 \\
\hline Delta (AY.9) & 983 & 951 & 96.7 & 32 & 3.3 & 36 & 3.6 \\
\hline Delta (AY.10) & 983 & 951 & 96.7 & 32 & 3.3 & 36 & 3.6 \\
\hline
\end{tabular}


Table 1. Cont.

\begin{tabular}{|c|c|c|c|c|c|c|c|}
\hline \multirow[b]{2}{*}{ Variant } & \multicolumn{7}{|c|}{ Spike Protein } \\
\hline & C/H-CrUPs & $\begin{array}{c}\text { Same } \\
\text { C/H-CrUPs }\end{array}$ & $\begin{array}{l}\% \text { of Same } \\
\text { C/H-CrUPs }\end{array}$ & $\begin{array}{c}\text { New } \\
\text { C/H-CrUPs }\end{array}$ & $\begin{array}{l}\% \text { of New } \\
\text { C/H-CrUPs }\end{array}$ & $\begin{array}{c}\text { Lost } \\
\text { C/H-CrUPs }\end{array}$ & $\begin{array}{c}\% \text { of Lost } \\
\text { C/H-CrUPs }\end{array}$ \\
\hline Delta (AY.11) & 983 & 951 & 96.7 & 32 & 3.3 & 36 & 3.6 \\
\hline Eta (B.1.525) & 990 & 956 & 96.5 & 34 & 3.4 & 31 & 3.1 \\
\hline Iota (B.1.526) & 984 & 960 & 97.5 & 24 & 2.4 & 27 & 2.7 \\
\hline Kappa (B.1.617.1) & 985 & 964 & 97.8 & 21 & 2.1 & 23 & 2.3 \\
\hline Lambda (C.37) & 982 & 949 & 96.6 & 33 & 3.4 & 38 & 3.9 \\
\hline Mu (B.1.621) & 983 & 953 & 96.9 & 30 & 3.1 & 34 & 3.4 \\
\hline Omicron (B.1.1.529) & 983 & 868 & 88.3 & 115 & 11.7 & 119 & 12.1 \\
\hline
\end{tabular}

These mutations seem to have a dramatic effect on the Spike protein C/H-CrUPs map. Compared to the wild-type Spike sequence, we found that 115 (new) C/H-CrUPs were created and $119 \mathrm{C} / \mathrm{H}-\mathrm{CrUPs}$ were lost, almost twice as many when compared to the Alpha variant (51 and $56 \mathrm{C} / \mathrm{H}-\mathrm{CrUPs}$, respectively), and almost four times as many, compared to the other variants (Table 1 ). The distribution of these new $\mathrm{C} / \mathrm{H}-\mathrm{CrUPs}$ shows that the majority carry 6 amino acids in length (Figure S4).

\subsection{Omicron-Specific C/H-CrUPs That belong to the Receptor Binding Domain}

SARS-CoV-2 belongs to the $\beta$ coronavirus group, which uses the plasma membrane receptor of Angiotensin-Converting Enzyme 2 (ACE2) to recognize and bind to the target cell [4]. The viral Spike protein attaches to ACE2 receptor by a Receptor Binding Domain (RBD) defined from amino acid position F318 to F541 [4,5]. The amino acid residues from W436 to Q506 inside RBD shape the Receptor Binding Motif (RBM), which carries 11 contact positions with ACE2 [5]. The RBD region has received great attention, as it seems to be a major target of antibodies against the virus and other therapeutic interventions [6-8].

In the RBD region, the Omicron variant carries 15 mutations, 10 of which are identified in the RBM area (Figure 1A). This results in the identification of the highest number of newly constructed C/H-CrUPs in the RBD/RBM region, as compared to all other previous virus variants examined (Table S1). Table 2 describes all the new, herein identified, $\mathrm{C} / \mathrm{H}-$ CrUPs of Omicron variant in Spike's RBD region, in comparison to the Alpha and Delta variants, which represent two of the most predominant variants of the virus in human populations. Hence, it was proven that, in contrast to Alpha and Delta variants, at the end of Omicron variant RBM area from 440 to 508 amino acid position, 8 novel mutations were identified, resulting in the production of 28 new $\mathrm{C} / \mathrm{H}-\mathrm{CrUPs}$. The most important finding is that in Omicron variant, for the first time, new $\mathrm{C} / \mathrm{H}-\mathrm{CrUPs}$ including two or three mutant amino acids were generated, with the peptides " $Q A G N^{*} K^{*} P^{\prime}$, " $N^{*} K^{*} P C N^{\prime}$, " $L K^{*} S Y S^{*} F^{\prime \prime}$ and " $K^{*} S Y S^{*} F R^{* \prime}$ " being characteristic examples, as a result of the accumulation of multiple mutations in the positions $440,446,477,478$ and $493-505$. These novel C/HCrUPs that contain several mutated amino acids could not be found in any other virus variants previously. Taking into consideration recent data about virus infectivity, the multimutated, new, C/H-CrUP collection seems to radically change the structure and the epitope regions of end positions of the RBM area in the Omicron variant, causing a serious compromise of its antigenic capacity and facilitating the immune escape of the virus [9]. 


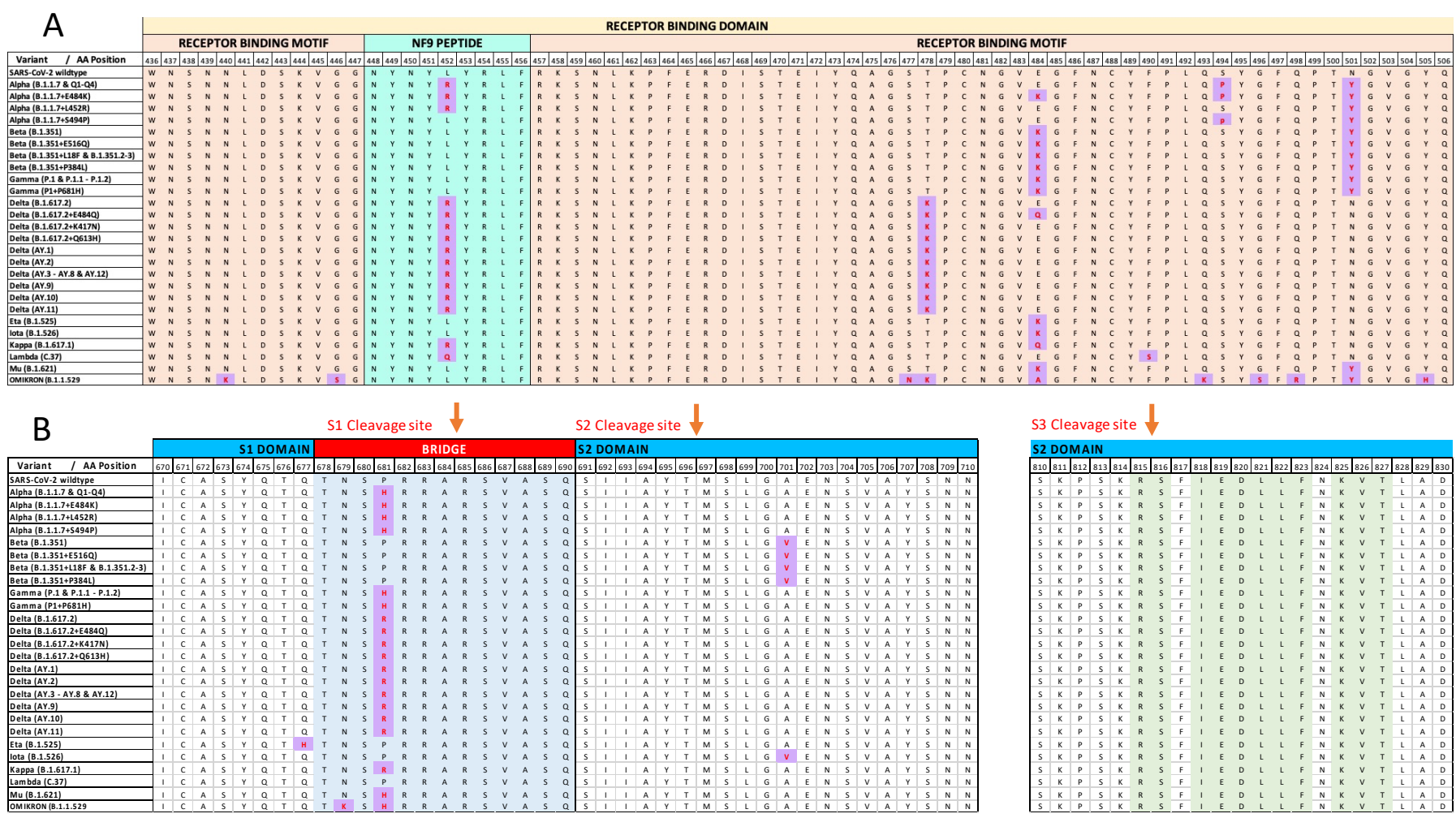

Figure 1. Mutations in different virus variants. (A) The mutations of the Receptor-Binding Motif (RBM) included in the Receptor-Binding Domain (RBD) are presented. (B) The mutations around the Spike cleavage sites are presented. Purple blocks mark the point mutation sites in the variants. Green colors indicate the Universal Peptides of the Spike proteins from Figure S2. Yellow colors mark the Receptor-Binding Domain of Spike protein interaction with ACE2. Pink colors mark the Receptor-Binding Motif. Cyan colors indicate the NF9 peptide, while light blue colors mark the Bridge between S1 and S2 domains. Red-colored arrows indicate the cleavage sites. With different colors in the upper side of the alignment, the different domains of the Spike protein are presented.

Table 2. C/H-CrUPs constructed aroud the mutations in RBD of Alpha, Delta and Omicron SARS$\mathrm{CoV}-2$ variants.

\begin{tabular}{|c|c|c|c|c|c|c|c|c|c|}
\hline \multicolumn{5}{|c|}{ Alpha Variant } & \multicolumn{5}{|c|}{ Delta Variant } \\
\hline C/H-CrUP & Position & Mutation & $\begin{array}{c}\text { New } \\
\text { C/H-CrUPs }\end{array}$ & Position & $\mathrm{C} / \mathrm{H}-\mathrm{CrUP}$ & Position & Mutation & $\begin{array}{c}\text { New } \\
\text { C/H-CrUPs }\end{array}$ & Position \\
\hline GNYNYL & 447 & \multirow{6}{*}{ L452R } & GNYNYR & 447 & PGQTGKI & 412 & \multirow{5}{*}{ K417N } & & \\
\hline NYNYLY & 448 & & & & GQTGKIA & 413 & & GQTGNI & 413 \\
\hline & & & YNYRY & 449 & & & & QTGNIA & 414 \\
\hline NYLYRL & 450 & & NYRYRL & 450 & TGKIAD & 415 & & TGNIAD & 415 \\
\hline YLYRLF & 451 & & YRYRLF & 451 & GKIADY & 416 & & GNIADY & 416 \\
\hline \multirow[t]{2}{*}{ LYRLFR } & 452 & & & & & & & & \\
\hline & & & & & GNYNYL & 447 & \multirow{6}{*}{ L452R } & GNYNYR & 447 \\
\hline CNGVEG & 480 & \multirow{5}{*}{ E484K } & CNGVKG & 480 & NYNYLY & 448 & & & \\
\hline NGVEGF & 481 & & NGVKGF & 481 & & & & YNYRY & 449 \\
\hline \multirow[t]{3}{*}{ GVEGFN } & 482 & & GVKGFN & 482 & NYLYRL & 450 & & NYRYRL & 450 \\
\hline & & & KGFNC & 484 & YLYRLF & 451 & & YRYRLF & 451 \\
\hline & & & & & LYRLFR & 452 & & & \\
\hline
\end{tabular}


Table 2. Cont.

\begin{tabular}{|c|c|c|c|c|c|c|c|c|c|}
\hline \multicolumn{5}{|c|}{ Alpha Variant } & \multicolumn{5}{|c|}{ Delta Variant } \\
\hline C/H-CrUP & Position & Mutation & $\begin{array}{c}\text { New } \\
\text { C/H-CrUPs }\end{array}$ & Position & $\mathrm{C} / \mathrm{H}-\mathrm{CrUP}$ & Position & Mutation & $\begin{array}{c}\text { New } \\
\text { C/H-CrUPs }\end{array}$ & Position \\
\hline YFPLQS & 489 & \multirow{12}{*}{$\begin{array}{l}\text { S494P } \\
\text { N501Y }\end{array}$} & YFPLQP & 489 & & & & & \\
\hline FPLQSY & 490 & & FPLQPY & 490 & YQAGST & 473 & \multirow{6}{*}{ T478K } & YQAGSK & 473 \\
\hline PLQSYG & 491 & & PLQPYG & 491 & & & & QAGSKP & 474 \\
\hline QSYGF & 493 & & QPYGF & 493 & AGSTPC & 475 & & AGSKPC & 475 \\
\hline SYGFQP & 494 & & PYGFQP & 494 & & & & GSKPCN & 476 \\
\hline GFQPTN & 496 & & & & STPCN & 477 & & & \\
\hline FQPTNG & 497 & & & & & & & KPCNG & 478 \\
\hline \multirow[t]{2}{*}{ QPTNGV } & 498 & & & & & & & & \\
\hline & & & QPTr & 498 & & & & & \\
\hline PTNGVG & 499 & & PTrG & 499 & & & & & \\
\hline TNGVGY & 500 & & TrGV & 500 & & & & & \\
\hline NGVGYQ & 501 & & rGVG & 501 & & & & & \\
\hline \multicolumn{10}{|c|}{ Omicron variant } \\
\hline C/H-CrUP & Position & Mutation & $\begin{array}{c}\text { New } \\
\text { C/H-CrUPs }\end{array}$ & Position & $\mathrm{C} / \mathrm{H}-\mathrm{CrUP}$ & Position & Mutation & $\begin{array}{c}\text { New } \\
\text { C/H-CrUPs }\end{array}$ & Position \\
\hline NLCPFG & 334 & \multirow{5}{*}{ G339D } & NLCPFD & 334 & IYQAGS & 472 & \multirow{5}{*}{$\begin{array}{l}\text { S477N } \\
\mathrm{T} 478 \mathrm{~K}\end{array}$} & & \\
\hline LCPFGE & 335 & & LCPFDE & 335 & YQAGST & 473 & & YQAGN & 473 \\
\hline PFGEVF & 337 & & PFDEV & 337 & & & & QAGNKP & 474 \\
\hline FGEVFN & 338 & & FDEVFN & 338 & AGSTPC & 475 & & & \\
\hline \multirow[t]{2}{*}{ GEVFNA } & 339 & & DEVFNA & 339 & STPCN & 477 & & NKPCN & 477 \\
\hline & & & & & & & & KPCNG & 478 \\
\hline VLYNSA & 367 & \multirow{10}{*}{$\begin{array}{l}\text { S371L } \\
\text { S373P } \\
\text { S375F }\end{array}$} & VLYNLAP & 367 & & & & & \\
\hline LYNSAS & 368 & & & & CNGVEG & 480 & \multirow{4}{*}{ E484A } & CNGVAG & 480 \\
\hline YNSASF & 369 & & YNLAPF & 369 & NGVEGF & 481 & & NGVAGF & 481 \\
\hline \multirow[t]{2}{*}{ NSASFST } & 370 & & & & GVEGFN & 482 & & GVAGFN & 482 \\
\hline & & & LAPFFT & 371 & & & & VAGFNC & 483 \\
\hline ASFSTF & 372 & & APFFTF & 372 & & & & & \\
\hline \multirow[t]{2}{*}{ SFSTFK } & 373 & & & & CYFPLQ & 488 & \multirow{10}{*}{$\begin{array}{l}\text { Q493K } \\
\text { G496S } \\
\text { Q498R } \\
\text { N501Y } \\
\text { Y505H }\end{array}$} & CYFPLK & 488 \\
\hline & & & FFTFK & 374 & YFPLQS & 489 & & YFPLKS & 489 \\
\hline \multirow[t]{2}{*}{ STFKC } & 375 & & FTFKCY & 375 & FPLQSY & 490 & & FPLKSY & 490 \\
\hline & & & & & PLQSYG & 491 & & & \\
\hline PGQTGKI & 412 & \multirow{6}{*}{ K417N } & & & & & & LKSYSF & 492 \\
\hline \multirow[t]{2}{*}{ GQTGKIA } & 413 & & GQTGNI & 413 & QSYGF & 493 & & KSYSFR & 493 \\
\hline & & & QTGNIA & 414 & SYGFQP & 494 & & SYSFRP & 494 \\
\hline TGKIAD & 415 & & TGNIAD & 415 & YGFQPT & 495 & & YSFRPT & 495 \\
\hline \multirow[t]{2}{*}{ GKIADY } & 416 & & GNIADY & 416 & GFQPTN & 496 & & & \\
\hline & & & & & FQPTNG & 497 & & FRPTY & 497 \\
\hline
\end{tabular}


Table 2. Cont.

\begin{tabular}{|c|c|c|c|c|c|c|c|c|c|}
\hline \multicolumn{10}{|c|}{ Omicron variant } \\
\hline $\mathrm{C} / \mathrm{H}-\mathrm{CrUP}$ & Position & Mutation & $\begin{array}{c}\text { New } \\
\text { C/H-CrUPs }\end{array}$ & Position & $\mathrm{C} / \mathrm{H}-\mathrm{CrUP}$ & Position & Mutation & $\begin{array}{c}\text { New } \\
\text { C/H-CrUPs }\end{array}$ & Position \\
\hline WNSNN & 436 & \multirow{8}{*}{$\begin{array}{c}\text { N440K } \\
\text { G446S }\end{array}$} & WNSNKL & 436 & QPTNGV & 498 & & RPTYGV & 498 \\
\hline SNNLDS & 438 & & SNKLDS & 438 & PTNGVG & 499 & & & \\
\hline \multirow[t]{2}{*}{ NNLDSK } & 439 & & NKLDSKV & 439 & TNGVGY & 500 & & TYGVGH & 500 \\
\hline & & & KLDSKVS & 440 & NGVGYQ & 501 & & & \\
\hline LDSKVG & 441 & & & & GVGYQP & 502 & & GVGHQ & 502 \\
\hline DSKVGG & 442 & & DSKVSG & 442 & VGYQPY & 503 & & VGHQPY & 503 \\
\hline KVGGNY & 444 & & KVSGNY & 444 & GYQPYR & 504 & & & \\
\hline VGGNYN & 445 & & VSGNYN & 445 & YQPYRV & 505 & & HQPYR & 505 \\
\hline GGNYNY & 446 & & & & & & & & \\
\hline
\end{tabular}

The original and newly constructed C/H-CrUPs around the native and mutant sites of RBD region of SARS-CoV-2 Spike protein in Alpha, Delta and Omicron variants are presented. With the red colors, the mutant amino acids in wild-type $\mathrm{C} / \mathrm{H}-\mathrm{CrUPs}$ and in the newly constructed peptides are marked.

Remarkably, RBM area contains 11 out of the 12 contact points of viral Spike protein with the ACE2 cellular receptor. Among them, 7 contact points remained intact, while 4 mutations in positions Q493K, Q498R, N501Y and Y505H were identified, resulting in the construction of 17 new C/H-CrUPs (Table 3). N501Y mutation was found to be a major determinant of increased viral transmission, due to the improved binding affinity of Spike protein to ACE2 cellular receptor [10]. These findings indicate that virus binding to ACE2 receptor is notably affected by $\mathrm{C} / \mathrm{H}-\mathrm{CrUP}$-specific mutations that can likely strengthen Spike-ACE2 protein-protein interaction(s).

Table 3. C/H-CrUPs around SARS-CoV-2 RBD contact positions.

\begin{tabular}{|c|c|c|c|c|c|c|c|c|c|c|c|c|}
\hline \multicolumn{8}{|c|}{ WILD-TYPE } & \multicolumn{5}{|c|}{ OMICRON VARIANT } \\
\hline $\begin{array}{c}\text { Contact } \\
\text { Positions }\end{array}$ & \multicolumn{6}{|c|}{ C/H-CrUPs } & Mutations & \multicolumn{5}{|c|}{ Newly Constructed C/H-CrUPs } \\
\hline N439 & AWNSN & WNSNN & SNNLDS & NNLDSK & & & & & & & & \\
\hline Y449 & KVGGNY & VGGNYN & GGNYNY & GNYNYL & NYNYLY & & & & & & & \\
\hline Y453 & NYNYLY & NYLYRL & YLYRLF & LYRLFR & YRLFRK & & & & & & & \\
\hline F486 & NGVEGF & GVEGFN & GFNCY & FNCYF & & & & & & & & \\
\hline N487 & GVEGFN & GFNCY & FNCYF & & & & & & & & & \\
\hline Y489 & GFNCY & FNCYF & CYFPLQ & YFPLQS & & & & & & & & \\
\hline Q493 & CYFPLQ & YFPLQS & FPLQSY & PLQSYG & QSYGF & & Q493K & CYFPLK & YFPLKS & FPLKSY & LKSYSF & KSYSFR \\
\hline Q498 & SYGFQP & YGFQPT & GFQPTN & FQPTNG & QPTNGV & & Q498R & KSYSFR & SYSFRP & YSFRPT & FRPTY & RPTYGV \\
\hline T500 & YGFQPT & GFQPTN & FQPTNG & QPTNGV & PTNGVG & TNGVGY & & & & & & \\
\hline N501 & GFQPTN & FQPTNG & QPTNGV & PTNGVG & TNGVGY & NGVGYQ & N501Y & FRPTY & RPTYGV & TYGVGH & & \\
\hline Y505 & TNGVGY & NGVGYQ & GVGYQP & VGYQPY & GYQPYR & YQPYRV & Y505H & TYGVGH & GVGHQ & VGHQPY & HQPYR & \\
\hline
\end{tabular}

The original and newly constructed $\mathrm{C} / \mathrm{H}-\mathrm{CrUPs}$ residing around the native and contact positions of the SARS$\mathrm{CoV}-2$ Spike protein RBD region. The $\mathrm{C} / \mathrm{H}-\mathrm{CrUPs}$ of wild-type and Omicron variant are presented. With red colors, the mutant amino acids in wild-type $\mathrm{C} / \mathrm{H}-\mathrm{CrUPs}$ and in the newly constructed peptides are marked.

Interestingly, an important amino acid sequence in the RBM area is the "NYNYLYRLF" peptide (from 448 to 456 position). This Tyrosine (Y)-enriched peptide carries two contact sites (Y449 and Y453), and it is known as the NF9 peptide [11]. It seems to affect antigen recognition, by being an immunodominant HLA*24:02-restricted epitope identified by $\mathrm{CD} 8^{+} \mathrm{T}$ cells. Of note, NF9 presents immune stimulation activity, and increases cytokine production derived from $\mathrm{CD} 8^{+} \mathrm{T}$ cells, such as IFN- $\gamma$, TNF- $\alpha$ and IL-2 [12]. In contrast to Delta, in the Omicron variant the NF9 amino acid content is not changed by any mutation 
detected, thus suggesting that the NF9 peptide could induce early immune system activation and efficient cytokine production, leading to a faster immune response, and thus reducing SARS-CoV-2 virus pathogenicity.

\subsection{C/H-CrUPs Altered Architecture around the Spike-Cleavage Site(s) of the Omicron Variant}

The molecular mechanism of Spike protein's proteolytic activation has been shown to play a crucial role in the selection of host species, virus-cell fusion, and the viral infection of human lung cells [13-15]. Spike protein [SPIKE_SARS2 (P0DTC2)] contains three cleavage sites (known as S-cleavage sites) crucial for the virus fusion to the host cell: the $R^{685} \downarrow S$ and $\mathrm{R}^{815} \downarrow S$ positions that serve as direct targets of the Furin protease, and the $\mathrm{T}^{696} \downarrow \mathrm{M}$ position that can be recognized by the TMPRSS2 protease [16-18].

In these cleavage sites, the Omicron variant carries only the critical mutation $\mathrm{P} 681 \mathrm{H}$, which also appears in the Alpha variant (Figure 1B). Strikingly, in contrast to the Delta variant, which contains the P681R mutation, the $\mathrm{P} 681 \mathrm{H}$ mutation constructs several new $\mathrm{C} / \mathrm{H}-\mathrm{CrUPs}$ in the Alpha and Omicron variants, thus indicating their dispensable contribution to virus fusion to the host cell (Table 4).

Table 4. C/H-CrUPs arround the Spike protein cleavage sites.

\begin{tabular}{|c|c|c|c|c|}
\hline Cleavage Site & Mutation & Variant & Position & New C/H-CrUPs \\
\hline \multirow{4}{*}{$R^{685} \downarrow S$} & P681R & Delta & 680 & SRRRAR $\downarrow S$ \\
\hline & \multirow{3}{*}{ P681H } & \multirow{3}{*}{ Alpha Omicron } & 677 & QTNSH \\
\hline & & & 678 & TNSHR \\
\hline & & & 680 & SHRRAR \\
\hline $\mathrm{T}^{696} \downarrow \mathrm{M}$ & A701V & Beta & \multicolumn{2}{|r|}{ None } \\
\hline $\mathrm{R}^{815} \downarrow \mathrm{S}$ & None & None & \multicolumn{2}{|r|}{ None } \\
\hline
\end{tabular}

\section{Conclusions}

Core Unique Peptides constitute a distinct and important group of peptides within a proteome. The identification of CrUPs in an organism (e.g., virus, microbe, or mutant protein) against a distinct proteome of another organism is a completely novel approach, which could prove useful for the understanding of the action of microorganisms, the association of novel pharmacological targets with therapies, and the design of novel vaccines. It could be employed in many different kinds of diseases, such as cancer, athropozoans diseases, the design of vaccines for pathogenic viruses, and the identification of new antigenic epitopes capable for the development of new diagnostic or therapeutic antibodies. Therefore, we applied this dynamic and novel strategy, for the first time, in the identification of CrUPs derived from SARS-CoV-2 against the human proteome [1]. In that study, we analyzed all the CrUP peptides of all SARS-CoV-2 variants against the proteome of the host organism, which in our case was Human sapiens. Remarkably, this approach clearly revealed the immune escaping capacity, the contagious power and the high pathogenicity of Delta variant, in contrast to other variants. Notably, these findings have been confirmed by epidemiological data concerning the course of the disease.

In the present study, we engaged this approach to the analysis of the SARS-CoV-2 Omicron variant. The analysis of $\mathrm{C} / \mathrm{H}-\mathrm{CrUP}$ landscapes in the heavily mutated SARS-CoV2 Omicron variant Spike protein unveiled that the Omicron variant, by the generation of novel multi-mutated $\mathrm{C} / \mathrm{H}-\mathrm{CrUPs}$, could escape the immune system defense mechanisms, while these $\mathrm{C} / \mathrm{H}-\mathrm{CrUP}$-specific mutations could facilitate more efficient virus binding to the ACE2 cellular receptor, and a more productive fusion of the virus to the host cell. Most importantly, in contrast to the Delta variant, the intact NF9 peptide in the Omicron variant, 
which has a known immunostimulatory effect, suggests that Omicron exhibits reduced pathogenicity as compared to Delta.

Supplementary Materials: The following supporting information can be downloaded at: https: / / www.mdpi.com/article/10.3390/vaccines10030357/s1. Figure S1: Uniquome creation algorithm; Figure S2: Extracting CrUPs of Target vs Reference Proteome; Figure S3: Alignment of the SARSCoV-2 Spike protein (SPIKE_SARS2, PODTC2) of the 26 variants, together with the wild-type Spike Protein (SPIKE_SARS2, P0DTC2); Figure S4: Length distribution of Omicron variant Spike protein C/H-CrUPs; Table S1: New C/H-CrUPs located in the RBD and RBM regions of the Spike protein across virus variants.

Author Contributions: Conceptualization, V.P., E.K. and G.T.T.; methodology, V.P. and E.K.; investigation, V.P., E.K. and G.T.T.; visualization, E.K., D.J.S. and G.T.T.; supervision, G.T.T.; writing—original draft, D.J.S. and G.T.T.; writing—review and editing, D.J.S. and G.T.T. All authors have read and agreed to the published version of the manuscript.

Funding: This research received no external funding.

Institutional Review Board Statement: Not applicable.

Informed Consent Statement: Not applicable.

Data Availability Statement: All data of the present article are available in the main text or in the supplementary materials.

Conflicts of Interest: The authors declare no conflict of interest.

\section{Abbreviations}

UPs: Unique Peptides; CrUPs: Core Unique Peptides; C/H-CrUPs: SARS-CoV-2 Core Unique Peptides against Human Proteome; RBD: Receptor Binding Domain; RBM: Receptor Binding Motif.

\section{References}

1. Pierros, V.; Kontopodis, E.; Stravopodis, D.J.; Tsangaris, G.T. Unique Peptide Signatures of SARS-CoV-2 Against Human Proteome Reveal Variants' Immune Escape and Infectiveness. bioRxiv 2021. [CrossRef]

2. Wang, L.; Cheng, G. Sequence analysis of the emerging SARS-CoV-2 variant Omicron in South Africa. J. Med. Virol. 2022, 94, 11728-11733. [CrossRef] [PubMed]

3. Kontopodis, E.; Pierros, V.; Anagnostopoulos, A.; Stravopodis, D.J.; Papassideri, I.; Vorgias, C.; Tsangaris, G.T. Data Processing Approach for the Construction and Evaluation of an Organism's UNIQUOME with Comparative Analysis for the Human, Rat and Mouse Uniquomes. In Proceedings of the XIII. Annual Congress of the European Proteomics Association: From Genes via Proteins and their Interactions to Functions, Potsdam, Germany, 24-28 March 2019.

4. Shang, J.; Ye, G.; Shi, K.; Wan, Y.; Luo, C.; Aihara, H.; Geng, Q.; Auerbach, A.; Li, F. Structural basis of receptor recognition by SARS-CoV-2. Nature 2020, 581, 221-224. [CrossRef] [PubMed]

5. Hatmal, M.M.; Alshaer, W.; Al-Hatamleh, M.A.I.; Hatmal, M.; Smadi, O.; Taha, M.O.; Oweida, A.J.; Boer, J.C.; Mohamud, R.; Plebanski, M. Comprehensive Structural and Molecular Comparison of Spike Proteins of SARS-CoV-2, SARS-CoV and MERS-CoV, and Their Interactions with ACE2. Cells 2020, 9, 2638. [CrossRef] [PubMed]

6. Chen, Y.; Zhang, Y.N.; Yan, R.; Wang, G.; Zhang, Y.; Zhang, Z.-R.; Li, Y.; Ou, J.; Chu, W.; Liang, Z.; et al. ACE2-targeting monoclonal antibody as potent and broad-spectrum coronavirus blocker. Signal Transduct. Target. Ther. 2021, 6, 315. [CrossRef] [PubMed]

7. Zahradnik, J.; Marciano, S.; Shemesh, M.; Zoler, E.; Harari, D.; Chiaravalli, J.; Meyer, B.; Rudich, Y.; Li, C.; Marton, I.; et al. SARS-CoV-2 variant prediction and antiviral drug design are enabled by RBD in vitro evolution. Nat. Microbiol. 2021, 6, 1188-1198. [CrossRef] [PubMed]

8. Hastie, K.M.; Li, H.; Bedinger, D.; Schendel, S.L.; Dennison, S.M.; Li, K.; Rayaprolu, V.; Yu, X.; Mann, C.; Zandonatti, M.; et al. Defining variant-resistant epitopes targeted by SARS-CoV-2 antibodies: A global consortium study. Science 2021, 374, 472-478. [CrossRef] [PubMed]

9. Chen, J.; Wang, R.; Gilby, N.B.; Wei, G.-W. Omicron Variant (B.1.1.529): Infectivity, Vaccine Breakthrough, and Antibody Resistance. J. Chem. Inf. Model. 2022, 62, 412-422. [CrossRef] [PubMed]

10. Liu, Y.; Liu, J.; Plante, K.S.; Plante, J.A.; Xie, X.; Zhang, X.; Ku, Z.; An, Z.; Scharton, D.; Schindewolf, C.; et al. The N501Y spike substitution enhances SARS-CoV-2 infection and transmission. Nature 2022, 602, 294-299. [CrossRef] [PubMed] 
11. Motozono, C.; Toyoda, M.; Zahradnik, J.; Saito, A.; Nasser, H.; Tan, S.T.; Ngare, I.; Kimura, I.; Uriu, K.; Kosugi, Y.; et al. SARS-CoV-2 spike L452R variant evades cellular immunity and increases infectivity. Cell Host Microbe 2021, 29, 1124-1136.e11. [CrossRef] [PubMed]

12. Kared, H.; Redd, A.D.; Bloch, E.M.; Bonny, T.S.; Sumatoh, H.; Kairi, F.; Carbajo, D.; Abel, B.; Newell, E.W.; Bettinotti, M.P.; et al. SARS-CoV-2-specific CD8+ T cell responses in convalescent COVID-19 individuals. J. Clin. Investig. 2021, 131, 1124-1136.e11. [CrossRef] [PubMed]

13. Peacock, T.P.; Goldhill, D.H.; Zhou, J.; Baillon, L.; Frise, R.; Swann, O.C.; Kugathasan, R.; Penn, R.; Brown, J.C.; Sanchez-David, R.Y.; et al. The furin cleavage site in the SARS-CoV-2 spike protein is required for transmission in ferrets. Nat. Microbiol. 2021, 6, 899-909. [CrossRef] [PubMed]

14. Whittaker, G.R. SARS-CoV-2 Spike and its Adaptable Furin Cleavage Site. Lancet Microbe 2021, 2, e488-e489. [CrossRef]

15. Shang, J.; Wan, Y.; Luo, C.; Ye, G.; Geng, Q.; Auerbach, A.; Li, F. Cell entry mechanisms of SARS-CoV-2. Proc. Natl. Acad. Sci. USA 2020, 117, 11727-11734. [CrossRef] [PubMed]

16. Hoffmann, M.; Kleine-Weber, H.; Schroeder, S.; Krüger, N.; Herrler, Y.; Erichsen, S.; Schiergens, T.S.; Herrler, G.; Wu, N.-H.; Nitsche, A.; et al. SARS-CoV-2 Cell Entry Depends on ACE2 and TMPRSS2 and Is Blocked by a Clinically Proven Protease Inhibitor. Cell 2020, 181, 271-280.e8. [CrossRef] [PubMed]

17. Hoffmann, M.; Kleine-Weber, H.; Pohlmann, S. A Multibasic Cleavage Site in the Spike Protein of SARS-CoV-2 Is Essential for Infection of Human Lung Cells. Mol. Cell 2020, 78, 779-784.e5. [CrossRef] [PubMed]

18. Takeda, M. Proteolytic activation of SARS-CoV-2 spike protein. Microbiol. Immunol. 2022, 66, 15-23. [CrossRef] [PubMed] 